\title{
The Motivational Potential of Human Resource Development: Relationships Between Perceived Opportunities for Professional Development, Job Crafting and Work Engagement
}

Naomi Grosze Nipper MSc

Tilburg University, The Netherlands

\author{
Dr. Jessica van Wingerden MBA $\mathrm{MCC}^{2,3}$ (Corresponding author) \\ Schouten Global, Centre of Research, Knowledge and Innovation, The Netherlands \\ Erasmus University Rotterdam, The Netherlands \\ E-mail: Jessica.vwingerden@sn.nl; jessica.vanwingerden@gmail.com
}

Prof. dr. Rob Poell ${ }^{1}$

Tilburg University, The Netherlands

Received: April 30, 2018 Accepted: May 11, 2018 Published: May 25, 2018

doi:10.5296/ijld.v8i2.13197ＵRL: https://doi.org/10.5296/ijld.v8i2.13197

\begin{abstract}
The importance of work engagement for organizational success in a rapidly changing economy has been emphasized in literature for several decades. A possible strategy for organizations to strengthen employees' work engagement may be related to their professional development. Based on the job crafting and job demands-resources literatures, we hypothesize that perceived opportunities for professional development have a positive relationship with work engagement and that this relationship is partially mediated by employees' job crafting behavior. To test the hypothesized relationships, we conducted a bootstrapping analysis using a sample of 859 employees working in various sectors and organizations in The Netherlands. The outcomes revealed that job crafting partially mediated the relationship between perceived opportunities for professional development and employees' work engagement. More specifically, two job crafting strategies were the strongest mediators in the relationship between perceived opportunities for professional
\end{abstract}


development and work engagement, namely increasing structural job resources and increasing challenging job demands. Theoretical contributions, limitations, suggestions for future research and practical implications are discussed.

Keywords: Opportunities for professional development; job crafting, work engagement, mediation, human resource development

\section{Introduction}

Over the last decade, research has revealed that work engagement has positive outcomes for both employees and organizations (Bakker \& Demerouti, 2014). Therefore, organizations have become interested in the concept of work engagement (World Economic Forum, 2015) and in ways to enhance employees' work engagement. One possible strategy to strengthen work engagement may be related to employee's professional development (Hobfoll, 1989). Employees' professional development can be facilitated by organizations, for example via training and/or coaching (top-down approach). Employees can also proactively take charge of their professional development themselves. Job crafting is such a form of proactive employee behavior (Wrzesniewski \& Dutton, 2001). Job crafting is a way in which employees take the initiative to optimize their work situation, and hence learn (bottom-up approach). Employees who craft their job try to improve the fit between their work and their abilities, knowledge, passions and needs, which could be related to higher work engagement (Bakker \& Demerouti, 2007). Thus, learning both from a top-down and a bottom-up perspective can be important antecedents of employees' work engagement. In the present study, the aim is to assess how learning and development strategies, from both a top-down and a bottom-up approach, are related to work engagement. As far as we know, these proposed relationships have not yet been examined in earlier studies, although they could shed more light on the ways in which organizations can enhance employees' work engagement.

\section{Theory and Hypotheses Development}

\subsection{Opportunities for Professional Development: Learning From a Top-Down Approach}

Most organizations in Western society offer their employees opportunities for professional development via training, coaching and career management programs (Huang, 2001). This top-down facilitation of learning and development is beneficial for employees and organizations. For employees, professional development may produce new skills and knowledge, and in turn contribute to their sustainable employability. In addition, professional development reinforces employee motivation and feelings of competence (Bakker \& Demerouti, 2007). For organizations, offering opportunities for professional development helps ensure that employees are able to meet their job requirements and contribute to the organization goals (Huang, 2001; Meijman \& Mulder, 1998). Opportunities for professional development could have both an intrinsic and extrinsic motivational role (Bakker \& Demerouti, 2007; Ryan \& Deci, 2000). Opportunities for professional development may have an intrinsic motivational role since they enhance employees' learning, development, growth and feelings of competence. Work environments that fulfill employees' need for competence will foster intrinsic motivation and vitality (i.e., work engagement) (Ryan \& Deci, 2000; 
Ryan \& Frederick, 1997). For example, when employees use opportunities for professional development (e.g., workplace training) provided by organizations, it may strengthen the learning process of employees and thereby fulfill the need for competence, which ultimately may foster motivation and wellbeing of employees (Ryan \& Deci, 2000; Ryan \& Frederick, 1997). Furthermore, opportunities for professional development (e.g., workplace coaching) may have an extrinsic motivational role too. Meijman and Mulder (1998) stated that when organizations offer their employees a sufficient amount of job resources, the willingness of employees to devote their effort and abilities to their work tasks will increase. Subsequently, employees' tasks will succeed and work goals will be reached. The extrinsic motivational potential provides help to employees (Schaufeli \& Bakker, 2004) in achieving their job tasks. Since employees will derive fulfillment from meeting work goals, they may become more engaged and committed within their job (Hackman \& Oldham, 2005). When employees perceive that their organization invests in their professional development, they may become more committed, more motivated and subsequently, more engaged.

\subsection{Job Crafting: Learning From a Bottom-Up Approach}

The term job crafting was first coined by Wrzesniewski and Dutton (2001) at the beginning of the $21^{\text {st }}$ century. When the term job crafting arose, employees were no longer considered to be passive operatives but as proactive employees who are able to make self-initiated bottom-up changes to their work. According to Wrzesniewski and Dutton (2001), employees can craft their job by implementing cognitive changes (e.g., changes in meaning of the job), physical changes (e.g., changes in form, number or scope of job tasks) and relational changes (e.g., changes in the nature of interactions at work) to attain important personal work goals. Another approach towards job crafting is related to the Job Demands-Resources (JD-R) theory (Bakker \& Demerouti, 2014). JD-R theory states that every job consists of both job demands and job resources, which can be influenced by job crafting. Thus, through job crafting, employees can change the level of job demands and job resources to align them with their personal needs and abilities.

The present study will focus on this approach, since it is well-validated and often utilized. According to the JD-R approach to job crafting, employees could craft their job by increasing structural resources (e.g., enhancing opportunities to develop yourself), increasing social job resources (e.g., asking their manager for feedback), increasing challenging job demands (e.g., starting a new project) or decreasing hindering job demands (e.g., reducing conflicts or workload) (Tims, Bakker \& Derks, 2012; Bakker \& Demerouti, 2014). Several studies, however, have shown ambiguous results of decreasing hindering job demands (Petrou, Demerouti, Peeters, Schaufeli, \& Hetland, 2012; Tims, Bakker, Derks \& Van Rhenen, 2013; Van Wingerden, Bakker \& Derks, 2017). Therefore, we will not include the decreasing hindering job demands dimension in the present study. The job crafting strategies increasing structural resources, increasing social job resources and increasing challenging job demands can also be seen as approaches to learning proactively within organizations. For example, when an employee wants to improve his or her skills in using Excel (i.e., increasing structural resources) he or she could try to learn from a colleague who is an expert in using the program. By proactively asking questions, trying to listen carefully and writing down practical 
suggestions, this employee can increase his or her Excel knowledge, skills and abilities. Another example of proactive learning within the organization is when an employee proactively asks his or her supervisor or colleague for performance feedback (i.e., increasing social job resources). When this employee receives information about his or her performance and suggestions on how to improve behavior, this employee may try to use this feedback and learn from it. An example of increasing challenging job demands is when an employee starts a new project at work where he or she needs to apply new knowledge and skills and collaborate with other employees to accomplish the project, which may stimulate a learning process. Thus, these three examples explain how the different job crafting strategies may also be ways to learn proactively within an organization.

\subsection{Learning From aTop-Down and Bottom-Up Approach as Related to Work Engagement}

Work engagement has been a subject of research since the early nineties of the last century (Kahn, 1992). Work engagement has been defined as a positive, fulfilling and work-related state of mind (Schaufeli \& Bakker, 2004). According to Schaufeli and Bakker (2004) work engagement is characterized by vigor (i.e., high levels of energy, willingness to put effort in one's work and mental resilience while working), dedication (i.e., strong involvement in one's work and feelings of enthusiasm, inspiration and pride while working) and absorption (i.e., high levels of concentration and engrossment while working). Over the years, this definition of work engagement has become well-validated and often utilized (Bakker \& Demerouti, 2014; Seppälä, et. al., 2009; Shimazu et al., 2008). A theory that helps us understand the antecedents and outcomes of work engagement is JD-R theory (Bakker \& Demerouti, 2014). JD-R theory explains how job characteristics such as job demands and resources influence employee motivation. Job demands are those organizational, physical and social aspects of a job that ask for energy. Job resources (e.g., opportunities for professional development) are those organizational, psychological, physical and social aspects of a job that provide energy and are functional in reducing job demands, stimulating growth and attaining work goals (Schaufeli \& Bakker, 2004). JD-R theory states that the combination of high job demands and high resources leads to high levels of motivation, involvement, and work engagement (Tuckey, Bakker, \& Dollard, 2012). Job demands and job resources are often determined or influenced by organizations. However, the conditions in the work environment can also be influenced by employees themselves (i.e., job crafting).

According to JD-R theory, job resources such as opportunities for professional development lead to positive outcomes, such as motivation and work engagement (Bakker \& Demerouti, 2007; Schaufeli \& Bakker, 2004; Van den Broeck, Van Steenkiste, De Witte \& Lens, 2008). Several studies have yielded evidence for the proposed positive relationship between opportunities for professional development and work engagement. For example, Schaufeli, Bakker and Van Rhenen (2009) showed in their study among managers and executives within a Dutch telecom organization that opportunities for professional development predicted work engagement over a one-year period. Furthermore, a two-year longitudinal study by Mauno, Kinnunen, and Ruokolainen (2007) among Finnish healthcare professionals showed that opportunities for professional development predicted their work engagement. Thus encouraging learning from a top-down approach may be an important strategy for 
organizations that want to enhance their employees' work engagement.

Employees can also proactively influence their work environment themselves via job crafting. Through job crafting, employees are able to optimize the fit between their job and their personal needs, preferences, passions and abilities (Tims et al., 2012; Wrzesniewski \& Dutton, 2001). In line with job crafting literature, employees can adapt their job demands and resources, and learn proactively in their job by doing so. As explained above, employees' different job crafting strategies and behaviors can also be seen as learning from a bottom-up approach. Employees who craft their job and subsequently learn proactively on the job, may be more likely to feel motivated, committed and engaged at work (Tims et al., 2012; Van Wingerden, Bakker \& Derks, 2017b). Earlier studies have confirmed the proposed positive relationship between job crafting and employees' work engagement. A study by Tims, Bakker, and Derks (2013) among employees within a chemical organization showed that job crafting was positively related to employee wellbeing, job satisfaction and work engagement. In a similar vein, a study by Van Wingerden, Bakker, and Derks (2016) among healthcare professionals revealed a positive relationship between increasing structural job resources and work engagement, and between increasing challenging job demands and work engagement. Furthermore, a job crafting intervention study by Van Wingerden, Bakker, and Derks (2017a) among teachers revealed not only a positive relationship between job crafting and work engagement but also that teachers' work engagement increased significantly after the job crafting intervention. In addition, the same study also revealed a positive relationship between opportunities for professional development and job crafting behavior. We propose that employees who perceive opportunities for professional development may want to benefit from it by applying the skills and knowledge learned within their job proactively to improve their work situation, which in turn may lead to higher levels of work engagement. All things considered, we hypothesize that within contemporary organizations perceived opportunities for professional development affect work engagement in two ways; directly and via increased job crafting behavior (see Figure 1). This leads to the following three hypotheses:

Hypothesis 1: Perceived opportunities for professional development are positively related to employees' level of work engagement.

Hypothesis 2: Employees' job crafting behavior is positively related to their level of work engagement.

Hypothesis 3: Employees' job crafting behavior partially mediates the relationship between perceived opportunities for professional development and employees' level of work engagement. 


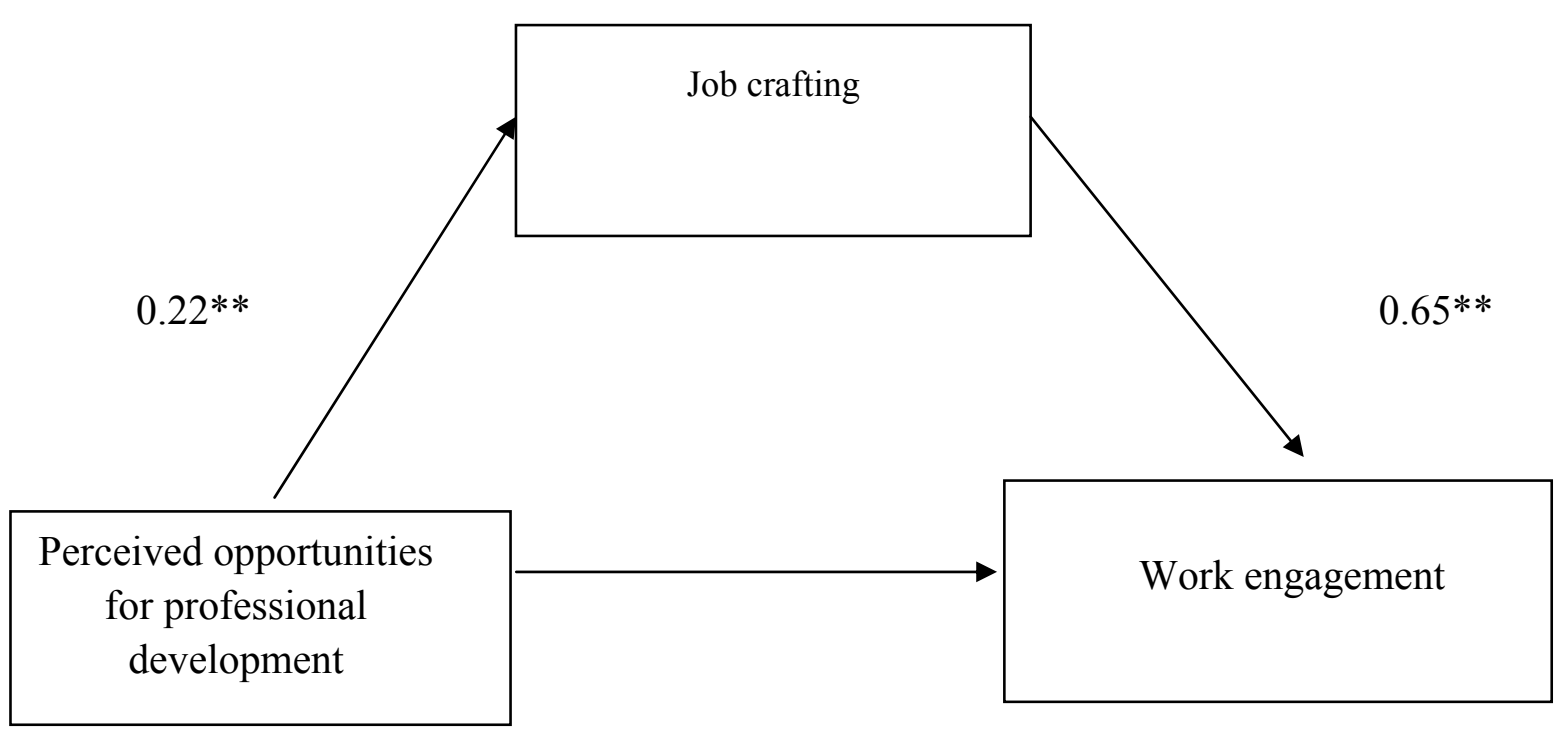

Figure 1. The proposed mediation model.

\section{Method}

\subsection{Design, procedure and participants}

The study was designed as a cross-sectional, quantitative, survey-based investigation using a convenience sample. Data were collected using an online questionnaire. The online questionnaire was posted on the website of a well-known Dutch HRD consultancy firm, and also announced through the company's digital newsletter and social media channels (i.e., Facebook, Twitter and LinkedIn). The announcement of the study contained a link, through which participants were able to read an introduction to the study and start the questionnaire. The participants were asked to fill in the questionnaire regarding their perceived opportunities for professional development, job crafting and work engagement. The questionnaire was available on the website for four weeks. Participants did not receive a monetary compensation for their participation. The participants also filled in an informed consent form.

In total, 859 professionals working in various sectors engaged in the study, 538 of which were female $(63 \%)$, and the mean age of the participants was 47.01 years $(S D=9.19)$. A majority of the participants ( $88 \%$ ) reported that they had obtained at least a bachelor's degree. With respect to sector, $15 \%$ of the participants $(n=126)$ worked in the educational sector, $14 \%(n=122)$ in the public service sector, $16 \%(n=133)$ in the healthcare sector, $12 \%(n=$ $104)$ in business services, $7 \%(n=63)$ in financial institutions and $36 \%(n=311)$ in the remaining sectors. The baseline characteristics of the study sample are presented in Table 1.

Table 1. Baseline Characteristics of the Study Population

\begin{tabular}{llll}
\hline Characteristic & N (\%) & Characteristic & N (\%) \\
\hline
\end{tabular}


Gender

Women

Men

Age

22-31 years

$32-41$ years

$59(7)$

$171(20)$

42-51 years

$340(39)$

52-61 years

62-70 years

Professional sector

Education

Healthcare

Public sector

Business services

Finances

Other

Sectors

$\begin{array}{ll}\text { Organization size } & \text { N (\%) } \\ \text { Self-employed } & 82(10) \\ \text { 2-99 employees } & 150(17) \\ 100-249 \text { employees } & 87(10) \\ 250-499 \text { employees } & 101(12) \\ 500-999 \text { employees } & 77(9) \\ 1000-1999 \text { employees } & 98(11) \\ 2000-4999 \text { employees } & 116(13) \\ 5000-9999 \text { employees } & 48(6) \\ >10000 \text { employees } & 100(12)\end{array}$

$258(30)$

$31(4)$

$126(15)$

$133(16)$

$122(14)$

104 (12)

$63(7)$

$311(36)$
2018, Vol. 8, No. 2

Supervisory position

Yes

$583(68)$

No

$276(32)$

\section{Education level}

Secondary school

Secondary vocational education

Higher vocational education

$463(54)$

University

Job tenure

$<2$ years

$115(14)$

2-3 years

$62(7)$

4-6 years

$131(15)$

7-10 years

$188(22)$

11-15 years

$146(17)$

$16>$ years

$217(25)$

\subsection{Measures}

Perceived opportunities for professional development was measured with three items from the scale of Bakker, Demerouti, Taris, Schaufeli and Schreurs (2003). An example item is: 


\section{Macrothink}

'My work offers me the possibility to learn new things'. A five-point scale was used with answers ranging from (1) totally disagree to (5) totally agree $(\alpha=.88)$.

Job crafting was measured with three subscales (increasing structural job resources, increasing social job resources and increasing challenging job demands) of the job crafting scale (Tims et al., 2012). Each subscale consisted of four items. An example item of increasing structural job resources $(\alpha=.74)$ is 'I try to learn new things at work', an example item of increasing social job resources $(\alpha=.76)$ is 'I ask my supervisor to coach me', and an example item of increasing challenging job demands $(\alpha=.78)$ is 'When there is not much to do at work, I see it as a chance to start new projects'. A five-point scale was used with answers ranging from (1) never to (5) very often.

Work engagement was measured with the three subscales (vigor, dedication and absorption) of the Utrecht Work Engagement Scale (UWES; Schaufeli, Bakker, \& Salanova, 2006). An example item of vigor $(\alpha=.89)$ is 'At my job, I feel strong and vigorous', an example of dedication $(\alpha=.91)$ is 'I am proud of the work that I do' and an example item of absorption $(\alpha=.75)$ is 'I am immersed in my work'. A seven-point scale was used with answers ranging from (0) never to (6) always.

\section{Results}

\subsection{Descriptive Statistics}

The means, standard deviations, reliabilities and correlations among all study variables are displayed in Table 2. Our central expectation is that perceived opportunities for professional development are directly related to work engagement $(\mathrm{H} 1)$, and that job crafting is also directly related to work engagement (H2). In addition, we propose that job crafting partially mediates the relationship between perceived opportunities for professional development and work engagement (H3). We examined the direct and indirect effects using Hayes' (2012) PROCESS macro, to test Hypotheses 1 through 3. 
Table 2. Correlations and Cronbach's Alphas (on the Diagonal) Among all Study Variables

\begin{tabular}{|c|c|c|c|c|c|c|c|c|c|}
\hline & $M$ & $S D$ & 1 & 2 & 3 & 4 & 5 & 6 & 7 \\
\hline 1 Professional Development & 3,8 & 0,9 & $(.88)$ & & & & & & \\
\hline 2 Job Crafting: structural resources & 4,3 & 0,5 & $.41^{* *}$ & $(.74)$ & & & & & \\
\hline 3 Job Crafting: social resources & 3,2 & 0,7 & $.25^{* *}$ & $.38^{* *}$ & $(.76)$ & & & & \\
\hline 4 Job Crafting: challenging demands & 3,9 & 0,7 & $.27^{* *}$ & $.50^{* *}$ & $.36^{* *}$ & $(.78)$ & & & \\
\hline 5 Vigor & 4,6 & 1,1 & $.53 * *$ & $.80^{* *}$ & $.27^{* *}$ & $.42 * *$ & $(.89)$ & & \\
\hline 6 Dedication & 4,8 & 1,2 & $.61^{* *}$ & $.42 * *$ & $.28^{* *}$ & $.40^{* *}$ & $.85^{* *}$ & $(.92)$ & \\
\hline 7 Absorption & 4,5 & 1,0 & $.41 * *$ & $.43 * *$ & $.21^{* *}$ & $.34 * *$ & $.74 * *$ & $.73 * *$ & $(.75)$ \\
\hline
\end{tabular}

Note. $* \mathrm{p}<.05, * * \mathrm{p}<.01$

\subsection{Professional Development, Job Crafting and Work Engagement}

We used a simple regression analysis to evaluate the effects of perceived opportunities for professional development and job crafting on work engagement. The results from the simple regression analysis indicated that there was a significant positive relationship between perceived opportunities for professional development and work engagement $(\mathrm{H} 1), b=.53, S E$ $=.03, p<.001$, and between job crafting and work engagement $(\mathrm{H} 2), b=.65, S E=.06, p$ $<.001$. Approximately $40 \%$ of the variance in work engagement was accounted for by the two predictors $\left(\mathrm{R}^{2}=.402\right)$. Thus, Hypothesis 1 and Hypothesis 2 were both confirmed by the data.

To test whether job crafting mediates the relationship between perceived opportunities for professional development and work engagement (H3), a mediation analysis was conducted (Macro Hayes model 4; Hayes, 2012). First, the regression of perceived opportunities for professional development on work engagement, ignoring the mediator, was significant, $b=$ $0.68, p<.001$. Second, the regression of perceived opportunities for professional development on the mediator, job crafting, was significant too, $b=0.22, p<.001$. Third, the egression of job crafting on work engagement, controlling for perceived opportunities for professional development was significant as well, $b=0.65, p<.001$. Finally, the analyses revealed that the regression of perceived opportunities for professional development on work engagement, controlling for the mediator, job crafting, was significant, $b=0.53, p<.001$. Overall, we concluded that job crafting partially mediated the relationship between perceived opportunities for professional development and work engagement, since the insignificance of the relationship between perceived opportunities for professional development and work engagement in the presence of the mediator, job crafting, could not be confirmed. Hence, the results confirmed Hypothesis 3 (See Figure 2). 


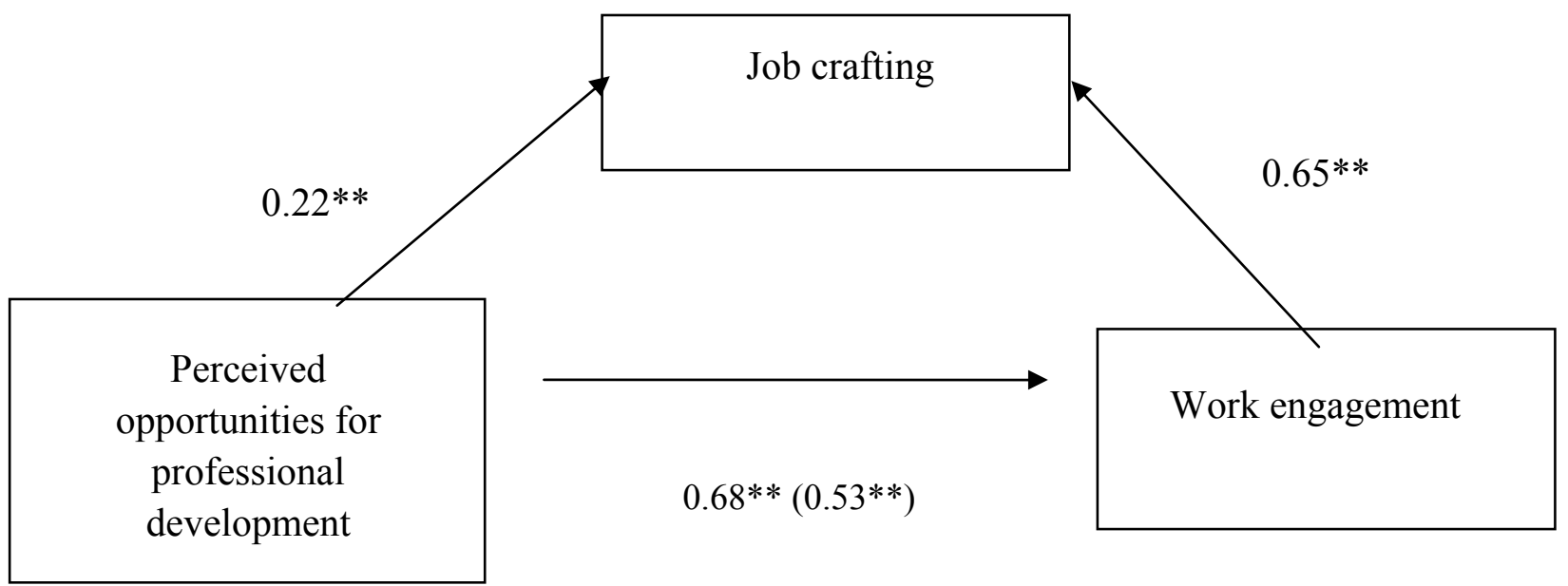

Figure 2. Outcomes of the analysis

Note: Unstandardized regression coefficients of perceived opportunities for professional development on work engagement, controlled for job crafting, stand between brackets. ${ }^{*} p$ $<.05, * * p<.001$

Furthermore, we examined how the three different job crafting strategies mediated the relationship between perceived opportunities for professional development and work engagement. With increasing structural job resources as a mediator in the relationship between perceived opportunities for professional development and work engagement, a significant positive indirect effect $\left(c^{\prime}=.1244\right)$ was found from the bootstrapping analysis, with a $95 \%$ confidence interval excluding zero (.0936 to .1611). With increasing social job resources as a mediator in the relationship between perceived opportunities for professional development and work engagement, a significant positive indirect effect $\left(c^{\prime}=.0448\right)$ was found from the bootstrapping analysis, with a 95\% confidence interval excluding zero $(.0237$ to .0710). With increasing challenging job demands as a mediator in the relationship between perceived opportunities for professional development and work engagement, a significant positive indirect effect $\left(c^{\prime}=.0929\right)$ was found from the bootstrapping analysis, with a 95\% confidence interval excluding zero (.0631 to .1291). The indirect effects of the mediators increasing structural job resources and increasing challenging job demands were higher than the indirect effect of the mediator increasing social job resources. Thus, the job crafting strategies increasing structural job resources and increasing challenging job demands were the strongest mediators in the relationship between perceived opportunities for professional development and work engagement.

\section{Discussion}

Professional development within contemporary organizations is assumed to be beneficial for both employees and employers. For employees, professional development reinforces motivation and feeling of competence (Colbert, Brown, Choi, \& Thomas, 2008); for employers, offering opportunities for professional development may ensure that employees 
are able to meet their job requirements and contribute to the organization goals (Huang, 2001; Meijman \& Mulder, 1998). Although human resource development has been considered a key issue within organizations (Huang, 2001), up till now little was known about how learning from both a top-down and bottom-up approach affects employee motivation and work engagement. Results of the present study demonstrate that perceived opportunities for professional development have a positive relationship with employees' work engagement via increased levels of job crafting behavior. This study furthermore found support for a direct and positive relationship between perceived opportunities for professional development and employees' work engagement. All things considered, this study supports our claim that perceived opportunities for professional development form an important predictor of employees' proactive behavior and work engagement.

\subsection{Theoretical Contributions}

A first theoretical contribution of the present study is that the outcomes revealed that job crafting partially mediates the relationship between perceived opportunities for professional development and employees' work engagement. Earlier studies had only revealed positive relationships between perceived opportunities for professional development and employees' work engagement (Schaufeli et.al, 2008; Mauno et al, 2007), and/or positive relationships between job crafting and employees' work engagement (Tims et al., 2012; Van Wingerden, Bakker, \& Derks, 2017b; Van Wingerden, Bakker, \& Derks; 2016). The present study enhances our understanding of the role of learning from both a top-down approach (opportunities for professional development) and a bottom-up approach (job crafting) in relation to employees' work engagement.

A second contribution of this study is that the outcomes showed that two job crafting strategies were the strongest mediators in the relationship between perceived opportunities for professional development and work engagement, namely increasing structural job resources and increasing challenging job demands. The job crafting strategy increasing social job resources was a less powerful mediator in the relationship between perceived opportunities for professional development and work engagement. These findings are in line with earlier research which revealed stronger and more significant correlations between increasing structural job resources and work engagement, and between increasing challenging job demands and work engagement, than between increasing social job resources and work engagement (Van Wingerden, Bakker, \& Derks, 2016).

\subsection{Limitations and Suggestions for Future Research}

Some limitations of this study need to be acknowledged. First, within the present study a cross-sectional dataset was used. Since the questionnaire was provided only once to the participants, it is not possible to make predictions and to infer causality. Future research could examine if there are causal relationships between perceived opportunities for professional development, job crafting and work engagement, for example, by using longitudinal study designs. Second, within the present study only self-reports were used, which may lead to common method bias. To avoid common method bias, future research could use different types of research methods, such as interviews and other-ratings from supervisors, colleagues 
and/or customers. The use of interviews or other-ratings may also create a broad and more objective view of the concepts measured. Third, the study sample consisted of employees who work in a variety of sectors and organizations; however, all participants were Dutch and mostly highly educated. This may limit the generalizability of the outcomes of this study. Future research may try to replicate our study among employees with different educational levels and who work and live in different countries.

Another question that may be interesting for future research is which type of opportunities for professional development (e.g, coaching, training and/or job rotation) are strongest related to employees' job crafting behavior and, subsequently, to their work engagement. In a similar vein, future research may determine which types of opportunities for professional development may stimulate proactive behavior among employees who work in different types of occupational groups and/or organizational levels. Detailed insights in these relationships may shed more light on the role of top-down and bottom-up learning in employees' work engagement.

\subsection{Practical Implications}

Gaining a better understanding of the influence of top-down and bottom-up learning on employees' work engagement has it practical implications. This study has revealed that the perception of top-down learning opportunities is directly positively related to work engagement, and indirectly via job crafting behavior. Therefore, offering opportunities for professional development might be worthwhile for organizations in various sectors. The results of this study showed that investing time and money in opportunities for professional development can positively impact employees' proactive behavior and work engagement. To stimulate employees' professional development, organizations may offer a wide range of human resource development activities, such as masterclasses, online and classroom training, coaching and/or job rotation. Learning and development departments in organizations may want to evaluate to what extent the human resource development activities offered meet the needs of their employees. These insights may help them optimize their learning and development policies and activities.

Organizations can also stimulate bottom-up learning by allowing employees to craft their job. Different types of strategies may contribute to creating awareness of opportunities to craft among employees (Van Wingerden \& Poell, 2017; Wrzesniewski, 2003). For example, managers or supervisors could share examples of their own job crafting strategies and related effects. Managers may also influence employees' perceived opportunities to craft by showing their appreciation for job crafting behavior within the organization by sharing job crafting examples of colleagues who work in different teams and/or departments. In addition, organizations can also stimulate job crafting behavior by offering job crafting training interventions, by which employees can experience how job crafting can be beneficial to them. Earlier studies have shown that investing in job crafting training interventions turned out to be worthwhile, because they are effective in increasing job crafting behavior and levels of work engagement (Gorden, 2015; Van den Heuvel, Demerouti, \& Peeters, 2012; Van Wingerden et al., 2017a), and job crafting intervention effects turned out to be sustainable 
over time (Van Wingerden et al., 2017b). We therefore strongly advocate the deliberate cultivation of job crafting behavior within organizations.

\section{References}

Bakker, A. B., Demerouti, E., Taris, T. W., Schaufeli, W. B., \& Schreurs, P. J. (2003). A multigroup analysis of the job demands-resources model in four home care organizations. International Journal of Stress Management, $10(1), \quad 16$. https://doi.org/10.1037/1072-5245.10.1.16

Bakker, A. B., \& Demerouti, E. (2007). The job demands-resources model: State of the art. Journal of managerial psychology, 22(3), 309-328. https://doi.org/10.1108/02683940710733115

Bakker, A. B. (2011). An evidence-based model of work engagement. Current Directions in Psychological Science, 20(4), 265-269. https://doi.org/10.1177/0963721411414534

Bakker, A. B., Tims, M., \& Derks, D. (2012). Proactive personality and job performance: The role of job crafting and work engagement. Human relations, 65(10), 1359-1378. https://doi.org/10.1177/0018726712453471

Bakker, A. B., \& Demerouti, E. (2014). Job demands-resources theory. In C. Cooper \& P. Chen (Eds.), Wellbeing: A complete reference guide (pp. 37-64). Chichester, UK: Wiley-Blackwell . https://doi.org/10.1002/9781118539415.wbwel1019

Colbert, J. A., Brown, R. S., Choi, S., \& Thomas, S. (2008). An investigation of the impacts of teacher-driven professional development on pedagogy and student learning. Teacher Education Quarterly, 35(2), 135-154. https://doi.org/10.1086/597493

Gordon, H, J., Demerouti, E., Le Blanc, P. M., \& Bipp, T. (2015). Job crafting and performance of Dutch and American health care professionals. Journal of Personnel Psychology, 14, 192-202 . https://doi.org/10.1027/1866-5888/a000138.

Hackman, J. R. \& Oldham, G. R. (2005). How Job Characteristics Theory Happened. The Oxford Handbook of Management Theory: The process of theory development, 151-170.

Hayes, A. F. (2012). PROCESS [Macro]. The Ohio State University.

Hobfoll, S. E. (1989). Conservation of resources: A new attempt at conceptualizing stress. American psychologist, 44(3), 513. https://doi.org/10.1037/0003-066X.44.3.513

Huang, T. C. (2001). The relation of training practices and organizational performance in small and medium size enterprises. Education+ Training, 43(8/9), 437-444. https://doi.org/10.1108/00400910110411620

Kahn, W. A. (1992). To be fully there: Psychological presence at work. Human relations, 45(4), 321-349. https://doi.org/10.1177/001872679204500402

Macey, W. H., \& Schneider, B. (2008). The meaning of employee engagement. Industrial and organizational Psychology, 1(1), 3-30. https://doi.org/10.1111/j.1754-9434.2007.0002.x 
May, D. R., Gilson, R. L., \& Harter, L. M. (2004). The psychological conditions of meaningfulness, safety and availability and the engagement of the human spirit at work. Journal of occupational and organizational psychology, 77(1), 11-37. https://doi.org/10.1348/096317904322915892

Mauno, S., Kinnunen, U., \& Ruokolainen, M. (2007). Job demands and resources as antecedents of work engagement: A longitudinal study. Journal of vocational behavior, 70(1), 149-171. https://doi.org/10.1016/j.jvb.2006.09.002

Meijman, T. F., \& Mulder, G. (1998). Psychological aspects of workload. Handbook of Work and Organizational Psychology. Volume, 2. East Sussex : Psychology press 1td.

Petrou, P., Demerouti, E., Peeters, M. C. W., Schaufeli, W. B., \& Hetland, J. (2012). Craftinga job on a daily basis: Contextual correlates and the link to work engagement. Journal of Organizational Behavior, 33, 1120-1141. https://doi.org/10.1002/job.1783

Ryan, R. M., \& Frederick, C. (1997). On energy, personality, and health: Subjective vitality as a dynamic reflection of well-being. Journal of personality, 65(3), 529-565. https://doi.org/10.1111/j.1467-6494.1997.tb00326.x

Ryan, R. M., \& Deci, E. L. (2000). Self-determination theory and the facilitation of intrinsic motivation, social development, and well-being. American psychologist, 55(1), 68. https://doi.org/10.1037/0003-066X.55.1.68

Schaufeli, W. B., Taris, T. W., Le Blanc, P., Peeters, M., Bakker, A. B., \& De Jonge, J.(2001). Maakt arbeid gezond? Op zoek naar de bevlogen werknemer [May work produce health? The quest for the engaged worker]. De PSycholoog.36, 422-428.

Schaufeli, W. B., \& Bakker, A. B. (2004). Job demands, job resources, and their relationship with burnout and engagement: A multi sample study. Journal of organizational Behavior, 25(3), 293-315. https://doi.org/10.1002/job.248

Schaufeli W. B., Bakker, A. B., \& Van Rhenen, W. (2008). How changes in job demands and resources predict burnout, work engagement, and sickness absenteeism. Journal of Organizational Behavior, 30, 893-917. https://doi.org/10.1002/job.595

Schaufeli, W. B., Bakker, A. B., \& Van Rhenen, W. (2009). How changes in job demands and resources predict burnout, work engagement, and sickness absenteeism. Journal of Organizational Behavior, 7, 893-917. https://doi.org/10.1002/job.595

Seppälä, P., Mauno, S., Feldt, T., Hakanen, J., Kinnunen, U., Tolvanen, A., \& Schaufeli, W. (2009). The construct validity of the Utrecht Work Engagement Scale: Multisample and longitudinal evidence. Journal of Happiness Studies, 10(4), 459-481. https://doi/10.1007/s10902-008-9100-y

Shimazu, A., Schaufeli, W. B., Kosugi, S., Suzuki, A., Nashiwa, H., Kato, A.,\& Goto, R. (2008). Work engagement in Japan: validation of the Japanese version of the Utrecht Work Engagement Scale. Applied Psychology, 57(3), 510-523. https://doi.org/10.1111/j.1464-0597.2008.00333.x 
Tims, M., Bakker, A. B., \& Derks, D. (2012). Development and validation of the job crafting scale. Journal of Vocational Behavior, 80(1), 173-186. https://doi.org/10.1016/j.jvb.2011.05.009

Tims, M., Bakker, A. B., \& Derks, D. (2013). The impact of job crafting on job demands, job resources, and well-being. Journal of occupational health psychology, 18(2), 230. https://doi.org/10.1037/a0032141

Tims, M., Bakker, A. B., Derks, D., \& Van Rhenen, W. (2013). Job crafting at the team and individual level: Implications for work engagement and performance. Group and Organization Management, 38, 427-454. https://doi.org/10.1177/1059601113492421

Tucky, M. R., Bakker, A., \& Dollard, M. F. (2012). Empowering leaders optimize working conditions for engagement: A multilevel study. Journal of Occupational Health Psychology, 17, 15-27. https://doi.org/10.1037/a0025942

Van den Broeck, A., Van Steenkiste, M., De Witte, H., \& Lens, W. (2008). Explaining the relationships between job characteristics, burnout, and engagement: The role of basic psychological need satisfaction. Work \& Stress, 22(3), 277-294. https://doi.org/10.1080/02678370802393672

Van Wingerden, J., Bakker, A. B., \& Derks, D. (2017a). Fostering employee well-being via a job crafting intervention. Journal of Vocational Behavior, 100, 164-174. https://doi.org/10.1016/j.jvb.2017.03.008

Van Wingerden, J., Bakker, A. B., \& Derks, D. (2017b). The longitudinal impact of a job crafting intervention. European Journal of Work and Organizational Psychology, 26, 107-119. https://doi.org/10.1080/1359432X.2016.1224233

Van Wingerden, J., Bakker, A. B. \& Derks, D. (2016). A test of a job demands-resources intervention. Journal of Managerial Psychology, 31, 3, 686-701. https://doi.org/10.1108/JMP-03-2014-0086

Van Wingerden, J., \& Poell, R. F. (2017). Employees' perceived opportunities to craft and in-role performance: The mediating role of job crafting and work engagement. Frontiers in Psychology. https://doi.org/10.3389/fpsyg.2017.01876

World Economic Forum (2015). What does employee engagement actually mean? Retrieved April 30, 2017, from https://www.weforum.org/agenda/2015/12/what-does-employee-engagement-actually-mean/

Wrzesniewski, A. (2003). Finding positive meaning in work. In K. S. Cameron, J. E. Dutton,\& R. E. Quinn (Eds.), Positive organizational scholarship: Foundations of a new discipline (pp. 298-308). San Francisco, CA: Berrett-Koehler.

Wrzesniewski, A., \& Dutton, J. E. (2001). Crafting a job: Revisioning employees as active crafters of their work. Academy of management review, 26(2), 179-201. https://doi.org/10.5465/AMR.2001.4378011 


\section{Copyright Disclaimer}

Copyright for this article is retained by the author(s), with first publication rights granted to the journal.

This is an open-access article distributed under the terms and conditions of the Creative Commons Attribution license (http://creativecommons.org/licenses/by/3.0/). 